\title{
Aulas de História: questões do/no tempo presente ${ }^{1}$
}

\section{History classes: issues from/at the present time}

\author{
Ana Maria Ferreira da Costa Monteiro ${ }^{2}$
}

\begin{abstract}
RESUMO
Este artigo tem por objetivo apresentar resultados de uma pesquisa voltada para a busca da compreensão de como/quais sentidos são induzidos por docentes no tempo presente, em diferentes contextos curriculares, no entendimento do "ensinar" enquanto fazer conhecer pelos sinais, produzir significados, histórica, política, teórica e culturalmente situados. Operando com o sentido de currículo como "lugar de fronteira", no qual são realizadas mediações didático-culturais, incorporamos a necessária articulação de referenciais teóricos disciplinares do campo do currículo/educação com aqueles do campo da historiografia, de forma a possibilitar a análise epistemológica do conhecimento produzido. A metodologia utilizada possibilitou a identificação de "professores de História marcantes". Suas aulas, após observação, foram analisadas buscando-se compreender a mobilização de saberes e referências culturais para tornar compreensível aos alunos a História ensinada no fazer curricular do/no tempo presente - o "contemporâneo do não contemporâneo". A questão da temporalidade foi considerada na análise das explicações realizadas pelos professores, entendida como dimensão estruturante do raciocínio histórico induzido em um contexto curricular específico no/do tempo presente, bem como as possibilidades e limites das mediações didático-culturais.
\end{abstract}

Palavras-chave: tempo presente; aula de História; narrativa; currículo; mediação didático-cultural.

DOI: $10.1590 / 0104-4060.42380$

1 Pesquisa financiada pelo Conselho Nacional de Desenvolvimento Científico e Tecnológico $(\mathrm{CNPq})$, por meio de bolsa de produtividade em pesquisa e de bolsa de iniciação científica (PIBIC), e pela Universidade Federal do Rio de Janeiro, por meio de bolsa de iniciação científica.

2 Universidade Federal do Rio de Janeiro. Centro de Filosofia e Ciências Humanas, Faculdade de Educação. Rio de Janeiro, Rio de Janeiro, Brasil. Avenida Pasteur, nº 250, sala A 111. CEP: 22290-240.E-mail: anamont@superig.com.br 


\begin{abstract}
This paper presents results of a research which aimed to understand which/ and how meanings are induced, at the present time, by teachers in different curricular contexts. We take for granted that teaching is an action which intends to make knowledge possible to be understood by other people, that is to produce historical, cultural, theoretical and politically situated meaning. Considering curriculum as a "frontier field" in which cultural didactic mediations take place, we articulate theoretical references from the curricular and educational fields with those from historiography to epistemologically analyze knowledge produced in History classes. The methodology relies on observation and registration of classes taught by "remarkable History teachers". In a second moment, narratives selected from these classes were the object of analyzes which aimed to understand the hybrid composition in which historical and cultural references are articulated so that History taught can be understood by the students. The specific aspects of the past brought about in the classes observed from/at the present - the "contemporary of the non contemporary" dimension - were considered in the analysis based on theoretical references from the present time, as well as possibilities and limits of cultural didactic mediations.
\end{abstract}

Keywords: present time; history classes; narrative; curriculum; cultural didactic mediation.

\title{
Aulas de História: questões do/no tempo presente
}

Questões relacionadas ao currículo e ao conhecimento escolar no ensino de História têm sido investigadas, no tempo presente, na busca de se compreender a relação dos docentes com os saberes que ensinam, considerando a originalidade e a especificidade epistemológica desse processo de produção. Essa perspectiva de abordagem situa-se no âmbito das possibilidades de entendimento do sentido de "ensino de" (FERREIRA et al., 2014) em nossas pesquisas. O conhecimento disciplinarizado - História - é entendido como produção dos docentes/agentes, culturais em diálogo com seus alunos, em contextos curriculares específicos. Estes podem estar constituídos em uma sala de aula, uma atividade museal, um texto de livro didático, uma dinâmica na modalidade Educação a Distância (EAD), considerados em seus aspectos contingenciais, nos quais circulam diferentes sentidos e demandas de conhecimento: fluxos oriundos dos conhecimentos científicos que se articulam com referências culturais dos diferentes sujeitos em diálogo e das instituições onde se efetivam as mediações/produções/ 
práticas articulatórias/negociações, no movimento constitutivo do "ensino de" no fazer curricular.

O foco da pesquisa volta-se, então, para a busca da compreensão de como/ quais sentidos são induzidos por docentes em diferentes contextos curriculares, ou seja, no entendimento do "ensinar" enquanto "fazer conhecer pelos sinais, produzir significados" (CHERVEL, 1990, p. 192) histórica, política e culturalmente situados. Isso implica considerar o currículo como "lugar de fronteira" 3 (MONTEIRO, 2007b, p. 75), em que articulamos referenciais teóricos disciplinares do campo do currículo/educação com aqueles do campo da historiografia, de forma a possibilitar a análise epistemológica do conhecimento produzido 4 .

Para essas análises temos operado teoricamente com autores que defendem a possível originalidade desta produção referenciada nos fluxos de cientificidade pertinentes. Entre eles, destacamos Chevallard (1991), Gabriel (2012), Monteiro (2007a, 2012), Monteiro e Penna (2011), Penna (2013), que oferecem contribuições relevantes para a investigação da epistemologia do conhecimento escolar (GABRIEL, 2006), mais especificamente na área do ensino de História.

Além dessas contribuições, necessitamos de instrumental que possibilite a investigação da questão da relação dos docentes com o conhecimento escolar na área do "ensino de História". Para a superação de perspectivas baseadas em filosofias do sujeito ou em concepções essencialistas de conhecimento, buscamos realizar abordagem que focaliza a relação sujeito/objeto de conhecimento/aluno constituintes do sistema didático em perspectiva histórica e construcionista no que se refere aos três elementos em sua relação.

Assim, a afirmação de que "[...] o professor não faz a transposição didática, mas trabalha na transposição didática que se iniciou na noosfera" (CHEVALLARD, 1991, p. 20), e que esta transposição é dinâmica e se renova continuamente, com fluxos do conhecimento científico (GABRIEL; MORAES, 2014, p. 31-32), produzido e atualizado a partir de contribuições da comunidade disciplinar de referência e de diferentes grupos sociais envolvidos, nos auxilia a compreender e a buscar ferramentas teóricas para a investigação de processo constituído historicamente em contextos nos quais diferentes referências circulam e interagem.

3 Fronteira no sentido de "border", lugar de marcação de diferenças, mas que também permite o encontro, as trocas; zona híbrida onde os contatos se pulverizam e se ordenam segundo micro-hierarquias, zona de imensas possibilidades de criação cultural. (MONTEIRO, 2007b, p. 75).

4 Aula refere-se, neste contexto, a eventos do fazer curricular, situados no tempo e no espaço, em contingências específicas, "[...] momento de transição no qual elementos do conhecimento históricos são apropriados pelos alunos e estes mesmos alunos constroem sua apropriação individual deste conhecimento que vai influenciar suas ações futuras, em outras palavras: o saber histórico de cada um destes alunos." (PENNA, 2013, p. 180). 
Considerar os docentes como sujeitos autores que atuam em contextos de autonomia relativa - não consideramos perspectivas voluntaristas que pressupõem uma autonomia ou emancipação ilusória - a partir de referências construídas ao longo de sua formação educacional e profissional, é outro desafio teórico a ser enfrentado. Este desafio aumenta em decorrência da perspectiva por nós assumida que considera a prática como espaço/tempo de mobilização de saberes, lugar teórico, portanto, no que se refere ao que é ensinado como também aos conhecimentos mobilizados para o ensino.

Nesse sentido, a pesquisa tem como objetivo analisar narrativas históricas, elaboradas por professores considerados "marcantes"s por seus alunos, narrativas estas que articulam conhecimentos historiográficos com saberes docentes, dos alunos e referências culturais do tempo presente, configurando mediações didático-culturais nas explicações produzidas.

Outra questão emergente relaciona-se à dimensão temporal constituinte das explicações sobre os temas em estudo. $\mathrm{O}$ conhecimento histórico exige operar com a localização no tempo e com as relações entre presente, passado e futuro, relações estas que, conforme proposto por Hartog (2013), através do conceito de "regime de historicidade", são fundamentais para a constituição e compreensão das construções elaboradas para a explicação histórica.

Assim, o constructo teórico desta investigação sobre o conhecimento histórico escolar implicou considerar a centralidade da questão da temporalidade e, mais especificamente, a questão do "tempo presente" no "ensino da" disciplina escolar História. Por um lado, os professores ensinam História no tempo presente, a partir de demandas emergentes que estão registradas nas diretrizes e propostas curriculares vigentes, exames vestibulares, avaliações sistêmicas, questionamentos dos alunos, tradições escolares, e que emergem dos debates políticos da sociedade na qual estão inseridos. Produzem o currículo ao articular os vários saberes que eles e seus alunos dominam com referências culturais que circulam no contexto em pauta e os fluxos do conhecimento científico - conteúdos que são mobilizados a partir de sua interpelação.

Em diálogo com contribuições de Koselleck (2006), sobre as categorias meta-históricas "espaço de experiência" e "horizonte de expectativa", de Hartog (2013), sobre "regime de historicidade", e de Dosse (2010, 2005), sobre "tempo presente", analisamos neste artigo contextos de produção de conhecimento histórico escolar em aulas de História considerando possibilidades e limites decorrentes de questões no/do tempo presente.

5 O conceito de "professor marcante" é utilizado em relação àqueles docentes identificados por estudantes como referência na construção de sua "boa" "relação com o saber" histórico escolar, inclusive indutora de opção de formação profissional em cursos de graduação em História. 
Na primeira parte, discutimos desafios da pesquisa sobre a produção do conhecimento histórico escolar no tempo presente explicitando a forma como estamos operando com este conceito no diálogo com autores que focalizam o tempo presente no campo da História e da educação. Na segunda parte, discutimos a questão dos saberes docentes no que se refere à relação com o saber e a metodologia utilizada para a identificação dos professores marcantes. Na terceira parte, analisamos algumas aulas de História com o objetivo de compreender como as questões no/do tempo presente se articulam com os diferentes fluxos de conhecimentos e referências no fazer curricular.

\section{História e ensino de História: desafios no/do tempo presente}

A questão da temporalidade como dimensão constitutiva da produção do conhecimento histórico tem sido objeto de estudos e reflexões de historiadores e filósofos entre os quais se destacam Ricoeur $(1983,2007)$, Koselleck (2006); Hartog (2013), Dosse (2005, 2010, 2012) e Rüsen (2001). De acordo com Koselleck (2006), a investigação sobre a semântica dos tempos históricos contribuiu e contribui para que seja possível avançar na busca da compreensão dos sentidos atribuídos pelos historiadores aos processos e fatos em análise, constituindo um novo paradigma para a escrita da História.

O "retorno da narrativa" ou a compreensão da sua centralidade na escrita da História teve em Ricoeur um autor referencial. Ao analisar a narrativa histórica, ele discutiu concomitantemente a questão do tempo histórico. É conhecida sua afirmação de que "a narrativa é a guardiã do tempo" pois "somente existiria tempo pensado, senão narrado". (RICOEUR, 1997, p. 417). A configuração do tempo histórico é realizada na narrativa pelo historiador, que articula espaço de experiência e horizonte de expectativas que definem um passado e um futuro tornados presentes. (DOSSE, 2010, p. 19) ${ }^{6}$.

No âmbito da construção da narrativa histórica, a questão da constituição da trama, do enredo expressa/produz a explicação histórica articulando explicação e compreensão, através da escrita: “[...] o modo do relato tem valor explicativo, ao menos pela utilização constante da conjunção de subordinação 'porque', que encobre e confunde duas funções distintas: a consecução e a

6 Dosse, em artigo recente publicado no Brasil em 2010, analisa as contribuições de Ricoeur, Certeau e Koselleck para a compreensão escrita da história e da dimensão temporal em sua produção. Neste texto utilizamos suas contribuições que articulam conceitos desses autores. Ver Dosse (2010). 
consequência." (DOSSE, 2010, p. 20). De acordo com Dosse, Ricoeur explica a operação historiográfica com base em Michel de Certeau, mas com algumas diferenciações. De acordo com Ricoeur (2000, p. 169 apud DOSSE, 2010, p. 24), são três etapas que a constituem: a fase arquivista, documentária, que se refere ao lugar, lugar social, que situa "a História como instituição de saber com sua lógica endógena própria." Neste lugar social, o historiador se pergunta: o que verdadeiramente aconteceu? em que a expressão verdadeiro/falso podem ser tomadas no sentido popperiano de refutável/verificável. (RICOEUR, 2000, p. 169 apud DOSSE, 2010, p. 24). É a primeira etapa do rompimento com a memória e de produção de História.

A segunda etapa se refere à busca da explicação/compreensão na qual o historiador aprofunda o rompimento com a memória, mobilizando diversos esquemas de inteligibilidade. Organiza indícios obtidos nas fontes em séries significativas, mobilizando temporalidades e escalas de análise. O terceiro nível é o da representação histórica, no qual a escrita é a principal ação, na qual o conceito de "representância" exprime a forma como o historiador lida com o real, é o "como se" e por meio da qual a relação com a materialidade representada nas fontes permite distinguir História de ficção, embora reconhecendo que são versões passíveis de reinterpretações, mas sempre comprometidas com a busca da verdade. (DOSSE, 2010, p. 25).

Essas contribuições para a epistemologia do conhecimento histórico podem ser apropriadas para a investigação da epistemologia do conhecimento escolar? São questões do tempo presente ${ }^{7}$ que nos afetam e desafiam para a pesquisa em ensino de História.

No Brasil, autores têm buscado investigar o conhecimento escolar em História tendo por base as contribuições da teoria da História e daqueles que teorizam as questões do currículo escolar. (GABRIEL, 2006; GABRIEL; MONTEIRO, 2014).

Defendemos que, em relação ao ensino de História, a questão da temporalidade é, também, central para a investigação e, assim, a noção de "tempo presente" se apresenta como desafio teórico ao ser acionada, não como referência de localização temporal em narrativas históricas de acontecimentos, mas como constituinte do pensamento histórico, do raciocínio, histórico, da "operação historiográfica escolar”. (PENNA, 2013).

O presente reinveste o passado de um horizonte histórico separado dele. Transforma a distância temporal morta em "transmissão geradora de sentido." (RICOEUR, 1991, p. 399).

7 Como questões do tempo presente nos referimos a aspectos teóricos de autores contemporâneos que se apresentam na produção curricular em disputa sobre sentidos de epistemologia da história, de conhecimento escolar e de prática docente, no caso em pauta neste artigo. 
Na pesquisa sobre a História ensinada no tempo presente, temos trabalhado com a concepção de Dosse, que defende " [...] a ideia de uma verdadeira singularidade da noção da História do tempo presente que reside na 'contemporaneidade do não contemporâneo', na espessura temporal do espaço de experiências e no presente do passado incorporado." (DOSSE, 2010, p. 6).

Nesse sentido, neste artigo não operamos com o conceito de tempo presente como a "História imediata" ou "contemporânea", mas como o tempo no qual "agimos" na operação historiográfica. Estamos nos referindo ao processo de produção da História que se instaura no momento da formulação de um problema e que nos remete a um passado que se constitui a partir da mobilização de nosso instrumental conceitual, documental e investigativo para a busca da explicação/ compreensão e escrita. Implica, também, considerar o "contemporâneo do não contemporâneo", conforme Dosse (2011), quando passado e futuro se tornam presentes como "espaço de experiências" e "horizonte de expectativas" a partir da mobilização realizada pelos historiadores e, no caso em pauta, professores.

Como já afirmamos, esse processo, que envolve aspectos epistemológicos integrantes e instituintes das narrativas históricas produzidas por historiadores, implica, necessariamente, no que se refere ao ensino, recontextualização e hibridização pelos professores e demais atores sociais em pauta, com aspectos relacionados às referências culturais - suas e de seu auditório e do contexto sociocultural mais amplo - para tornar possível a atribuição de sentidos ao objeto de estudo, em disputa com outros sentidos possíveis, mas fora do controle e do espectro curricular.

Entendemos que considerar a noção de tempo presente no "ensino de" implica também, necessariamente, a articulação com a noção de narrativa histórica (GABRIEL; MONTEIRO, 2014) constitutiva do discurso historiográfico, mediadora entre a História (vivida) e a produção de um saber para a construção de sentido do/no mundo. Assim, a produção de saberes no fazer curricular do ensino de História, objeto da investigação em pauta, envolve desafios teóricos no/do tempo presente a serem enfrentados na busca da compreensão das articulações possíveis entre historiografia e dinâmica cultural na produção de sentidos no ensino, o que induz ao questionamento de possibilidades e limites da consideração da didática como processo epistemológico e cultural. Sentido, entendido como "significado" e "orientação", perspectiva semiótica e ética condensadas em um mesmo enunciado. "Sentido articula percepção, interpretação, orientação e motivação, de maneira que a relação do homem consigo e com o mundo possa ser pensada e realizada na perspectiva do tempo." (RÜSEN, 2001, p. 156).

Defendemos que essas transformações, operadas a partir da articulação de diferentes saberes na "negociação de distância" (MEYER, 1998) entre professores e alunos, mediadas por suas referências culturais e profissionais - no caso dos 
docentes - podem produzir conhecimento original e consistente teoricamente: saberes docentes de autoria de professores.

\section{Professores marcantes: saberes docentes no ensino de História no/do tempo presente}

Para a realização desta investigação, um desafio tem sido identificar quais professores selecionar para a pesquisa. Os melhores? Os que desenvolvem um bom ensino? Referenciados por quem?

Nesse processo, utilizamos o conceito de "professores marcantes", ou seja, aqueles que "marcaram" seus alunos em aulas de História que se tornavam significativas para eles por meio do ensino realizado. Esse conceito contempla nosso objetivo de pesquisa que é buscar e analisar construções da História escolar que possam servir de referência para outros docentes em formação ou em atuação. Não é nosso objetivo identificar e denunciar erros ou equívocos, ou identificar aulas exemplares, modelos a serem seguidos. Buscamos narrativas de professores que, em seu enredo, explicam e auxiliam os alunos na compreensão da História ensinada, professores estes que foram considerados marcantes por seus alunos.

Na perspectiva que trabalhamos, temos considerado os docentes "autores" de suas aulas (MATTOS, 2006), uma vez que entendemos que o currículo escolar é um lugar de fronteira no qual se articulam diferentes conhecimentos, como já explicamos na parte inicial deste artigo. Assim, buscamos realizar a análise considerando as possibilidades de autoria, que implica "autorização" e "criação". Criação de conhecimento novo e autorização pois reconhecido por pares e avalizado pela instituição escolar ${ }^{8}$. (ANDRADE, 2014, p. 185-186).

Como metodologia, elaboramos um questionário que é respondido por estudantes do primeiro período de cursos de graduação em História e no qual estes são inquiridos sobre o fato de terem tido um professor de História marcante que os influenciou positivamente na escolha do curso de História para a realização da graduação. São duas páginas respondidas ainda no início do semestre de forma que a memória recupere indícios sobre a prática de docentes da Educação Básica. Na construção do questionário, operamos com contribuições de autores do tempo presente que pesquisam formação de professores. (TARDIF, 2002;

8 No contexto das políticas atuais, essa autoria vem sendo desconsiderada e negada e materiais didáticos com aulas prontas vêm sendo distribuídos e induzidos a serem utilizados pelos sistemas de avaliação. 
GAUTHIER, 1998; CUNHA, 1989)9. . Os estudantes escrevem sobre o porquê da escolha e as características desses professores. Em um segundo momento, numa segunda folha, assinalam características que consideram expressar a ação desses docentes ${ }^{10}$. Solicitamos, então, que eles informem o nome e escola do professor/a - quando foi possível localizar mais de 100 (cem) professores. Entre aqueles que receberam mais de uma indicação, selecionamos três com os quais estamos realizando a pesquisa.

Esta foi realizada em três etapas: primeiro realizamos uma entrevista na qual indagamos sobre características pessoais, formação e a atuação profissional para obter subsídios sobre o profissional e nos aproximarmos dele/a de forma relacional e participativa. Numa segunda etapa realizamos a observação das aulas, gravadas em áudio e transcritas para a análise, com o foco na atuação do professor. Não realizamos nenhuma intervenção deliberada embora tenhamos conhecimento de que nossa presença sempre gera alterações nos comportamentos. Temos percebido que os professores buscam mostrar o que fazem de melhor, o que tem se revelado um fator positivo em nossa metodologia de pesquisa. No terceiro momento, em outra entrevista, promovemos um processo de reflexão sobre a prática através do qual o professor analisa e explica como e por que agiu da maneira que foi observada, referenciais teóricos, sentidos que buscou induzir nas temáticas abordadas.

Nesta pesquisa não procuramos "bons professores", pois entendemos que esta adjetivação implica valores que variam de acordo com a concepção teórica sobre docência e currículo. O conceito criado identifica profissionais a partir da relação por eles estabelecida com os alunos e com o conhecimento ensinado, estrutura do sistema didático em análise. $\mathrm{O}$ estudante reconheceu neste profissional uma capacidade de atribuição de significado ao que era ensinado. Como fez isso? Como isso foi possível?

São opções realizadas no tempo presente, referenciadas em características culturais de alunos e professores e que são analisadas com base em referenciais teóricos do tempo presente, de autores que pesquisam a teoria da História e a docência.

A pesquisa para localizar os professores foi realizada no ano de 2013 e foram citados professores de alguns anos atrás. A distância temporal não prejudicou a lembrança dos alunos, como podemos perceber neste comentário feito pela professora:

9 No nosso entendimento, esses autores são autores do tempo presente na perspectiva do contemporâneo do não contemporâneo. São utilizados como referência para a pesquisa no tempo presente da sua realização.

10 Essa listagem foi construída a partir da leitura de textos teóricos de autores do tempo presente sobre ação docente. 
Ai eles me acharam lá no Facebook... é, por que que eu fui marcante? Provavelmente eu enchi o saco desse pessoal, né. Foi muito engraçado no outro dia que eu tinha esquecido a nota da "Caça ao tesouro" de uma turma. Ai eu postei lá no Face, pessoal, pessoal que fez a "Caça ao tesouro", lembra pra mim quanto, a nota que vocês tiraram. Mais de duzentas pessoas entraram lá. Eu lembro, eu tirei dois. Eu falei ué, o que é que o Igor está fazendo aqui? O pessoal que já foi meu aluno há mais de cinco anos atrás, quatro anos atrás. Olha, era eu e Rafael, bota nossa nota aí. Não esquece não... ${ }^{11}$

Referências do tempo presente no tempo presente, o contemporâneo do não contemporâneo.

\section{Aulas de História: questões no/do tempo presente}

Uma aula de História em turmas de segundo e terceiro anos do Ensino Médio em escola da rede privada de classe média, na zona norte da cidade do Rio de Janeiro. Que processos de racionalização pedagógica (SHULMAN, 1987, p. 12-19) para a produção do conhecimento escolar foram realizados? Como foram efetivadas as articulações referenciadas no tempo presente? Quais as técnicas argumentativas mais utilizadas e por quê? Como foi negociada a distância entre os alunos, a professora e os saberes? E a temporalidade? Como constitui e é constituída nas narrativas ali produzidas?

Temos um lugar: uma escola de Educação Básica com orientações em relação ao currículo a ser desenvolvido, opções que são recontextualizadas em decorrência da listagem de competências e habilidades que orientam o Exame Nacional de Ensino Médio (ENEM) ${ }^{12}$. Uma prática - prática docente de produção de sentidos sobre/com os saberes ensinados.

O tema abordado "o processo de independência das 13 Colônias Inglesas na América".

11 Aula realizada no dia 22/10/2014, turma 2001. A professora comenta uma atividade intitulada "Caça ao Tesouro", que ela costuma realizar com as turmas. Os alunos criam pistas referenciadas no conhecimento histórico em estudo e eles brincam no pátio para localizar as pistas e o tesouro. O grupo vencedor ganha um picolé. Essa atividade foi acompanhada por nós nos dias 17 e 18 de setembro de 2014.

12 ENEM: Exame realizado anualmente e que classifica os candidatos ao ingresso no Ensino Superior. A prova é organizada com base na teoria de resposta ao item. 
$\mathrm{D}^{13}$ : Ali, lembrando pra gente as treze colônias iniciais no litoral, a expansão, vamos lembrar também que eles têm uma cadeia de montanhas aqui. (D trabalha, nesse momento com um slide projetado no quadro com informações e mapa dos Estados Unidos) que dificultava esse processo de expansão inicialmente chamado Apalaches, certo? Essa cadeia de montanhas, devido à grande quantidade, grande concentração de gente nesse litoral eles partem para a área interna, tá. Eles vão buscar o interior ${ }^{14}$.

A professora inicia sua narrativa sobre a ocupação do território norte-americano e faz comparações com outros processos realizados na África e Américas portuguesa e espanhola.

D: A Independência, ela é antes da marcha para o oeste, tá legal? Primeiro eles se tornam independentes, depois eles vão marchar para o interior do território. Essa independência que eles vão fazer, ela tem um fator que provoca. Na verdade, quando a gente vai estudar história tem sempre algum fator que é o desencadeador, aquele fator que provoca alguma coisa, que faz a mudança naquela sociedade. Então quando eles vão se declarar independentes, de quem? A independência deles foi da Inglaterra. O que é que provocou a independência? Por que que eles vão buscar a independência se eles já tinham, por exemplo, na parte norte no território, eles já praticavam aqui o self government?

Aqui temos, entre outros aspectos, a preocupação da professora com a localização temporal dos acontecimentos narrados, preocupação com a sucessão, com a consecução e consequência. Ela não cita datas, mas sente a necessidade de situar no tempo os acontecimentos relatados. Referências aos processos realizados no contexto da emancipação das 13 colônias inglesas são trazidas para o presente, discursivamente, em narrativa por ela produzida. Podemos perceber que ela problematiza o processo da independência - embora não retome explicitamente a explicação do conceito de independência - conduzindo os alunos a refletir sobre a questão da causalidade.

13 A professora não será identificada na análise. A letra D de docente será utilizada para sua referência.

14 Aula realizada no dia 22/10/2014, na turma 2001. Os trechos citados a seguir foram extraídos da mesma aula. 
Ela afirma: "quando a gente vai estudar história tem sempre algum fator que é o desencadeador, aquele fator que provoca alguma coisa, que faz a mudança naquela sociedade".

Aqui a reiteração da causalidade em História, numa perspectiva pautada por um entendimento de que a História é processo que se desenvolve a partir das necessidades, interesses e ações sociais. Podemos perceber como, na sua narrativa, a explicação se articula com a busca da compreensão na construção do enredo, ou seja, o processo de lutas que constituiu o contexto do processo de independência das 13 colônias inglesas na América.

Encontramos, aqui, no movimento de problematizar o processo narrado, a mobilização de outros sujeitos e disputas que interferem na construção do enredo, em uma vinculação causal fato/consequência. (PERELMAN; OLBRECHTS-TYTECA, 1996, p. 308). É importante notar, também, que a narrativa para ser narrada exige a presença de sujeitos que, no caso em pauta, são "os países" Inglaterra e a França, que assumem posições de sujeitos deflagradores de ações. Perspectiva nominalista que pode suscitar incompreensões entre os alunos, mas ação muito frequente entre os professores de História.

D: Uma guerra. tá? Que não envolveu as treze colônias, mas uma guerra. Essa guerra, ela foi conhecida como Guerra dos Sete Anos (nome da guerra é escrito no quadro). Essa Guerra dos Sete Anos, ela vai envolver dois países. Ela envolveu a Inglaterra e ela envolveu a França. Então, olha só, para eu poder estudar a história dos Estados Unidos eu preciso entender o envolvimento da Inglaterra numa guerra, tá? Parece que é esquisito, né, mas eu não estou estudando a história deles, o que que eu tenho a ver com a Inglaterra? A questão é a seguinte. A Inglaterra controlava as colônias, certo? Mas ela se envolve numa guerra com a França pelo prazo de sete anos. O resultado dessa guerra foi o seguinte: a França perdeu. A Inglaterra, ela ganha, mas toda guerra traz um custo muito alto. Dinheiro. Ela precisava de dinheiro pra poder suprir esses gastos de guerra. E o que que a Inglaterra resolveu fazer? Resolveu arrancar esse dinheiro da sua área colonial (escrito no quadro). Nesse caso, especificamente, os Estados Unidos. Tudo bem? Deu para entender? França, qual é a consequência da França? Dívida de guerra. Mas qual é a consequência para a França? Vai explodir a Revolução Francesa.

A professora continua sua narrativa oral na qual ela relaciona as repercussões da Guerra dos Sete Anos entre Inglaterra e França nas 13 Colônias Inglesas na América. Ela trabalha as relações de causalidade - os fatores - que 
provocaram: a reação dos colonos e a luta pela independência e que, por outro lado, possibilitou a "explosão" (sic) da Revolução Francesa. Ela articula as relações de forma retroativa e não linear: para explicar a reação dos colonos, ela traz a "Inglaterra" para a trama e a demanda por recursos em razão do ônus da Guerra dos Sete Anos com a "França". Então, comenta a derrota da "França" e afirma que a dívida de guerra provoca a Revolução Francesa. Podemos inferir que os processos em pauta foram simplificados na sua explicação. Processos complexos, imbricados de forma aligeirada.

Numa tentativa de problematização, a professora pergunta e ela mesma responde, mantendo a atenção dos alunos ao seu relato. Os fatos narrados no tempo presente ocorreram no passado, em outro tempo, no século XVIII. Sua narrativa traz o passado para o presente na busca de torná-los possíveis de serem compreendidos por seus alunos no tempo presente. Além disso, e em decorrência disso, ela estabelece conexões com contextos da contemporaneidade - "a realidade do aluno" - que têm alguma relação com os fatos que são objeto de estudo. Os deslocamentos temporais no presente articulam fatos ocorridos em diferentes tempos do passado e isso é feito sem uma preocupação explícita da professora em situar as questões de forma mais clara.

Os alunos insistem em compreender o sentido do que está sendo narrado. Um deles pergunta:

Aluno: Por que rolou essa guerra?

D: Essa guerra é por disputa de território. Tanto que quando a guerra acaba, a França perde vários territórios. Um dos territórios que ela vai perder é aquela parte norte lá do Canadá.

Aluno: Ah, por isso ele tem uma partezinha francesa.

D: Por isso... exatamente. Por isso o Canadá tem dois idiomas, inglês e francês. Porque eles controlavam, com essa guerra eles acabam perdendo uma parte desse território e a Inglaterra ocupa o resto.

Aluno: É, a parte oeste...

A professora reitera a questão da disputa por territórios que, em um primeiro momento, teria sido a geradora dos conflitos. $\mathrm{O}$ aluno, em sua pergunta, opera com a relação causal como "fato/consequência". Mais à frente, a professora discute as Leis Intoleráveis e suas repercussões no processo de independência, mantendo a perspectiva relacional-causal. Continua sua narrativa e relata um fato interessante que ocorreu recentemente: relacionado aos eventos em pauta: 
D: Ninguém tinha certeza que essa coisa chamada "Festa do chá em Boston" tinha acontecido. Porque os colonos se fantasiaram de indio, entraram no navio e empurraram essas caixas dentro do mar. E ai a Companhia das Índias Orientais exigiu que os colonos pagassem. Os colonos disseram: a gente não paga porque não foi a gente que jogou nada. Quem jogou foram os índios, não fomos nós. Ai os colonos: Não tem como provar. Não foi ninguém daqui, nenhum colono fez isso. Mas claro que fizeram. E ai a Inglaterra teve que ressarcir a companhia. E tem, acho que uns há dez anos atrás, a Revista [...] publicou uma reportagem que um grupo de mergulhadores resolveu verificar se esse episódio chamado a Festa do Chá em Boston realmente aconteceu. Os caras mergulharam. Tem um pessoal ai que trabalha com mergulho e trabalha com História. É, são biólogos, são antropólogos, historiadores e trabalham com mergulho nessas áreas aonde naufragaram navios, aonde naufragaram, é, barcos menores, tá? Ai o cara foi lá... Sobraram vinte. Que que esse cara fez? Resgatou essas caixas e tentou vender isso lá nos Estados Unidos pra um museu por quinhentos mil dólares. Isso é uma grana, né?. Quase um milhão, não é isso? Mais ou menos um milhão de reais. $O$ museu disse que não pagava. Pagava, no máximo, por aquelas caixas que estavam quebradas, claro, né, estavam lá com aquelas, como é que é aquele "bagulhinho" do mar que gruda? Esqueci o nome...

Aluna: Coral.

D: Coral. Estava com coral preso. Ai o museu pagou 20 mil pelas 20 caixas que o cara achou. Vinte mil dólares

Alunos: Caraca...

D: É, pois é, pois é. Mas o cara pagou, o museu pagou. Isso está em exposição hoje lá. Porque isso aí era um mito, isso era uma lenda. Ninguém tinha certeza que tinha acontecido. Lembre-se que para a História, a gente precisa de documentos...

Aqui a professora traz para o tempo da aula no presente uma ilustração de um fato ocorrido recentemente e que atraiu a atenção dos alunos - o fato era muito curioso e, ao mesmo tempo, trouxe uma "prova" "documental" para justificar que a História narrada era História e não apenas memória. $\mathrm{O}$ fato do mergulhador encontrar as caixas serviu como prova para a garantia da veracidade do episódio relatado e, também, do relato da professora. A professora articula eventos do passado - "a festa do chá de Boston" com o episódio do tempo presente - os mergulhadores e as caixas encontradas na baía de Boston -, que chegaram a ela através da leitura de reportagem em revista semanal brasileira. Temos, aqui, uma ilustração da produção híbrida do conhecimento escolar em que referências culturais acessadas pela docente são articuladas aos conteúdos 
para torná-los possíveis de serem compreendidos. Mediação didático-cultural na produção curricular no tempo presente.

Com a narrativa deste caso inserida na aula, a professora atraiu o interesse dos alunos e, ao mesmo tempo, ilustrou a explicação sobre a diferença entre História e memória e o papel dos documentos na História. Nesse sentido, se revelou uma ação bem-sucedida para "negociar a distância" com seus alunos em relação ao conhecimento objeto de estudo.

A retórica é a negociação da distância entre os sujeitos. Esta negociação acontece pela linguagem (ou, de modo mais genérico, através $d a-$ ou de $u m a$ - linguagem), pouco importa se é racional ou emotiva. A distância pode ser reduzida, aumentada ou mantida consoante o caso. Um magistrado que pretenda suscitar a indignação, procura impedir quaisquer aproximação ou identificação entre o réu e os jurados. Em compensação, um advogado que pleiteia a favor de circunstâncias atenuantes, esforçar-se-á por encontrar pontos de contato entre os jurados e o acusado. (MEYER, 1998, p. 26-27).

Esta definição da retórica revelou-se muito profícua para pensar o trabalho do professor, como ele negocia diversas distâncias em sala de aula para conseguir propiciar uma aprendizagem significativa: a distância entre ele próprio e a turma, entre os saberes dos alunos e a História, entre o estranho e o familiar, o conhecido e o desconhecido...

Nesses exemplos foi possível perceber a produção do "conhecimento pedagógico do conteúdo". (SHULMAN, 1987, p. 12-19). Não basta conhecer a matéria para ensinar. É preciso compreender a estrutura da matéria a ser ensinada e qual o objetivo de se estar ensinando isso, e não outra coisa, para poder transformar o conhecimento a ser ensinado em uma forma própria que possibilite a compreensão de acordo com os objetivos e os alunos envolvidos.

\section{Considerações finais}

Nas narrativas da aula analisadas neste artigo, a professora buscou auxiliar os alunos a compreender o significado do processo que culminou com a independência das 13 Colônias Inglesas na América. Aulas no tempo presente, na perspectiva já citada (DOSSE, 2011), nas quais o não contemporâneo torna-se 
contemporâneo ao ser mobilizado por ela para tornar compreensíveis aos alunos os processos em estudo, tendo por base suas (dela e deles) referências culturais. Ela negocia com eles a distância entre o estranho e o familiar, entre o que sabem e o que desconhecem e, ao mesmo tempo, afirma sua autoridade ao deixar claro que domina os conhecimentos que são objeto de ensino.

Narrativas são construídas nas quais, por exemplo, o sentido das lutas dos colonos - que afirmam princípios e lutam por seus direitos - é enfatizado. No contexto histórico dado, ações foram possíveis, opções foram tomadas. Um enredo é apresentado, problematizado e o desfecho vai sendo compreendido pelos alunos. A narradora - a professora - conduz o fio da narrativa de acordo com seus objetivos, definidos a partir de demandas do currículo no tempo presente por ela apropriadas em decorrência de sua formação histórica e pedagógica.

O passado, tornado presente, contribui para possibilitar a produção de sentidos sobre os fatos estudados e, ao mesmo tempo, para a formação de valores por esses alunos: lutas dos colonos, a compreensão de que os sujeitos históricos fazem História... percepção, interpretação, orientação, motivação...

As aulas se configuram em um "espaço de experiências" em que se articulam experiências históricas de outros sujeitos de outras sociedades, culturas e tempos, com as dos alunos, vividas no tempo presente e mobilizadas em um "horizonte de expectativas": o sucesso nos exames do ENEM? A formação do cidadão crítico?

Mediações didático-culturais porque operadas para a produção de sentidos em aulas nas quais a autoria da professora/narradora é produzida em contexto dinâmico de articulação de diferentes saberes, mas no qual sua autoridade é argumento instituinte. $\mathrm{O}$ passado tornado presente contribuiu para a produção de sentidos, o que faz com que os alunos, possivelmente, a considerem uma professora marcante. A diferença entre presente e passado foi pouco explicitada? Reforço a uma perspectiva presentista? A pouca atenção a essa questão merece atenção e reflexão. A necessidade de possibilitar a produção de sentido torna o anacronismo inevitável? Ou podemos operar com o anacronismo racionalizado conforme propõe Dosse (2005)?

Contexto de grande complexidade, a produção do conhecimento escolar teve na análise retórica ferramenta metodológica profícua para a investigação das narrativas que articulavam subsídios teóricos da historiografia - contribuições sobre os fatos e conceitos estudados e, especialmente, as questões relacionadas com a dimensão temporal - e com as referências culturais dos alunos e professora, bem como outras presentes na sociedade, processo que estamos denominando "mediações didático-culturais". Questões teóricas do tempo presente que nos auxiliam a compreender e problematizar o ensino de História no tempo presente, lugar de fronteira. "arena política e cultural". 


\section{REFERÊNCIAS}

ANDRADE, L. T. de. Entre fazer e dizer: atividade docente e práticas pedagógicas escolares nos atos de escrita na formação. Raído, Dourados, MS, v. 8, n. 16, p. 177-196, jul./dez. 2014.

CHERVEL, A. A história das disciplinas escolares: reflexões sobre um campo de pesquisa. Teoria \& Educação, Porto Alegre: Pannonica Editora, n. 2, p. 177-229, 1990.

CHEVALLARD, Y. La transposición didáctica. Del saber sabio al saber enseñado. Buenos Aires: Aique Grupo Editor, 1991.

CUNHA, M. I. O bom professor e sua prática. 3. ed. Campinas, SP: Papirus, 1989.

DOSSE, F. De l'usage raisonné de l'anachronisme. EspacesTemps, n. 87/88, "Les voies traversières de Nicole Loraux", p. 156-171, 2005. (p. 163-164, tradução da autora).

DOSSE, F. Os três mastros entre dois recifes: a história entre vigilância e ficção. FERREIRA, M. de M. (Org.). Memória e identidade nacional. Rio de Janeiro: FGV Editora, 2010.328 p.

DOSSE, F. História do tempo presente e historiografia. Revista Tempo e Argumento. Revista do Programa de Pós-graduação em História, Florianópolis, v. 4, n. 1, p. 5-22, jan./jun. 2012.

FERREIRA, M. S. et al. Sentidos de "ensino de" Biologia e História: deslocando fronteiras. In: GABRIEL, C. T.; MORAES, L. M. S. de (Orgs.). Currículo e conhecimento: diferentes perspectivas teóricas e abordagens metodológicas. Rio de Janeiro: DP et alii/ FAPERJ, 2014. p. 81-98.

GABRIEL, C. T. O processo de produção de saberes no âmbito da disciplina de história: tensões e perspectivas. 2006. (mimeo).

GABRIEL, C. T. Que passados e futuros circulam nas escolas de nosso presente? GONÇALVES, M. de A. et al. Qual o valor da História hoje? Rio de Janeiro: Editora FGV, 2012. p. 215-240.

GABRIEL, C. T. et al. Pesquisa em ensino de História. Entre desafios epistemológicos e apostas políticas. Rio de Janeiro: Mauad X/ FAPERJ, 2014. 278 p.

GABRIEL, C. T.; MONTEIRO, A. M. F. C. Currículo de História e narrativa: desafios epistemológicos e apostas políticas. In: GABRIEL, C. T. et al. Pesquisa em ensino de História. Entre desafios epistemológicos e apostas políticas. Rio de Janeiro: Mauad X/ FAPERJ, 2014. $278 \mathrm{p}$.

GABRIEL, C. T.; MORAES, L. M. S. Conhecimento escolar e conteúdo: possibilidades de articulação nas tramas da didatização. In: GABRIEL, C. T.; MORAES, L. M. S. Currículo e conhecimento. Diferentes perspectivas teóricas e abordagens metodológicas. Rio de Janeiro: FAPERJ/DP et alii, 2014. p. 23-42. 
GAUTHIER, C. Por uma teoria da pedagogia. Pesquisas contemporâneas sobre o saber docente. Ijuí, RS: Editora UNIJUÍ, 1998.

HARTOG, F. Regimes de historicidade. Presentismo e experiências no tempo. Belo Horizonte: Autêntica Editora, 2013. (Coleção História e Historiografia).

KOSELLECK, R. Futuro Passado. Contribuição à semântica dos tempos históricos. Rio de Janeiro: Contraponto: Editora PUC Rio, 2006. 366 p.

MATTOS, I. R. Mas não somente assim! Leitores, autores, aula como texto e o ensino-aprendizagem de História. Tempo. Revista do Departamento de História da UFF, v. 11, p. 15-26, 2007.

MEYER, M. Questões de retórica. Linguagem, razão e sedução. Lisboa: Edições 70, 1998.

MONTEIRO, A. M. F. C. Professores de História: entre saberes e práticas. Rio de Janeiro: MAUAD Editora, 2007a.

MONTEIRO, A. M. F. C. Ensino de História: lugar de fronteira. ARIAS NETO, J. M. História: guerra e paz. ANPUH XXIII Simpósio Nacional de História. Londrina: ANPUH/ FINEP, 2007b. p. 71-97.

MONTEIRO, A. M. F. C.; PENNA, F. de A. Ensino de História: saberes em lugar de fronteira. Educação \&Realidade, Porto Alegre, v. 36, n. 1, p. 191-211, jan./abr. 2011.

PENNA, Fernando de Araújo. Ensino de História como operação historiográfica. Tese (Doutorado) - Programa de Pós-Graduação em Educação da Faculdade de Educação, UFRJ, Rio de Janeiro, 2013.

PERELMAN, C.; OLBRECHTS-TYTECA, L. Tratado da Argumentação: A Nova Retórica. São Paulo: Martins Fontes, 1996.

RICOEUR, P. Tempo e narrativa. Tradução de Roberto Leal Ferreira. Revisão técnica de Maria da Penha Villela-Petit. Campinas, SP: Papirus, 1997. Tomo III.

RICOEUR, P. A memória, a história, o esquecimento. Campinas, SP: Editora da UNICAMP, 2007.

RÜSEN, Jörn. Razão histórica. Teoria da história: os fundamentos da ciência histórica. Tradução de Estevão de Rezende Martins. Brasília: Ed. UNB, 2001, 194 p.

SHULMAN, L. Knowledge and teaching: foundations of the new reform. Harvard Educational Review, v. 57, n. 1, p. 1-21, Feb. 1987.

TARDIF, M. Saberes docentes e formação profissional. Petrópolis, RJ: Vozes, 2002.

Texto recebido em 03 de agosto de 2015. Texto aprovado em 23 de setembro de 2015. 